\title{
The Effect of Valsalva and Toynbee Maneuvers on Tympanometry Parameters in Normal and Retracted Tympanic Membrane
}

\author{
Yazeed Alshawi ${ }^{1 *}$, Abdulmalik Ismail ${ }^{2}$, Nora Almegil ${ }^{3}$ and Zaid almubarak ${ }^{4}$ \\ ${ }^{1}$ Department of Otology/ Neurotology, king Abdulaziz University Hospital, Saudi Arabia \\ ${ }^{2}$ Department of Otolaryngology and Head and Neck, Prince Sultan Military Medical City, Riyadh, Saudi Arabia \\ ${ }^{3}$ Department of Audiology, Security Forces Hospital, Riyadh, Saudi Arabia \\ ${ }^{4}$ Department of Otolaryngology and Head and Neck, Imam Abdulrahman Bin Faisal University, Dammam, Saudi Arabia
}

Submission: March 26, 2018; Published: April 17, 2018

*Corresponding author: Yazeed Ali alshawi, Senior registrar at Prince Sultan Medical Military Center, Otology/ Neurotology fellow at king Abdulaziz University Hospital, Riyadh, Saudi Arabia, Email: dr.alshawi@windowslive.com

\begin{abstract}
The Eustachian tube, also known as auditory tube, is a bony and fibro cartilagenous tube that connects the middle ear to the nasopharynx. It plays a major role in equalizing the pressure between the external environment and middle ear and in protecting the middle ear from nasopharyngeal secretions. Dysfunction of Eustachian tube may cause negative pressure to buildup in the middle ear, leading to retraction of the tympanic membrane or collection of fluid in the middle ear. The diagnosis of Eustachian tube dysfunction is important in understanding the pathogenesis of otitis media and in its management. Nowadays, numerous Eustachian tube function tests exist, one of the most commonly used is tympanometry which may be combined with Valsalva maneuver and Toynbee maneuver. Kumazawa et al. diagnosed Eustachian tube pathologies by asking his patients to perform Valsalva and Toynbee maneuvers and took tympanogram measurements for his patients. He then categorized his patients, based on their readings, into patient with Eustachian tube dysfunction, patients with normal Eustachian tubes and patients with patulous Eustachian tube. The purposes of the present study were to evaluate the variation in middle ear pressure in patients with type A tympanogram (normal tympanic membrane) and type C tympanogram (retracted tympanic membrane) during Eustachian tube function tests. Additionally, to evaluate the time effectiveness of Valsalva maneuver on pressure parameter and to compare these effects between type A and type C tympanogram. We found that, Valsalva maneuver had a significant effect on middle ear pressure in both normal population and on those with retracted tympanic. Although it did not in type A group, the effect of Valsalva maneuver lasted longer than 10 minutes in type C group. Further studies with a larger sample size and different tests of Eustachian tube function are recommended for better understanding of the duration of the effect of Valsalva maneuver on middle ear pressure.
\end{abstract}

\section{Introduction}

The Eustachian tube, also known as auditory tube, is a bony and fibrocartilagenous tube that connects the middle ear to the nasopharynx. It plays a major role in equalizing the pressure between the external environment and middle ear and to protect the middle ear from nasopharyngeal secretions [1]. Dysfunction of Eustachian tube may cause negative pressure to buildup in the middle ear, leading to retraction of the tympanic membrane or collection of fluid in the middle ear [2]. Eustachian tube dysfunction is considered one of the main factors for otitis media with effusion (OME), and secondary cholesteatoma [3]. The diagnosis of Eustachian tube dysfunction is important in understanding the pathogenesis of otitis media and in its management.

Nowadays, numerous Eustachian tube function tests exist, one of the most commonly used is tympanometry which may be combined with Valsalva maneuver (blowing against a closed mouth and nostrils, increasing the middle ear pressure) and Toynbee maneuver (swallowing while the mouth and nostrils are closed, decreasing the middle ear pressure) $[4,5]$. Kumazawa, et al. diagnosed Eustachian tube pathologies by asking his patients to perform Valsalva and Toynbee maneuvers and took tympanogram measurements for his patients. He then categorized his patients, based on their readings, into patient with Eustachian tube dysfunction, patients with normal Eustachian tubes and patients with patulous Eustachian tube [6].

The purposes of the present study is to evaluate the variation in middle ear pressure in patients with type A tympanogram (normal tympanic membrane) and type C tympanogram (retracted tympanic membrane) during Eustachian tube 
function tests, Valsalva, and Toynbee maneuvers. Additionally, to evaluate the time effectiveness of Valsalva maneuver on pressure parameter and to compare these effects between type A and type C tympanogram.

\section{Methodology}

\section{Objectives of the study}

Aim of the Study: To study the difference in the duration of the effect of Valsalva maneuver on middle ear pressure between type $\mathrm{A}$ and type $\mathrm{C}$ tympanograms.

\section{Secondary Objectives:}

a) To study the difference in effectiveness of Valsalva maneuver on middle ear pressure between type $\mathrm{A}$ and type $\mathrm{C}$ tympanograms.

b) To study the difference in effectiveness of Toynbee maneuver on middle ear pressure between type $\mathrm{A}$ and type $\mathrm{C}$ tympanograms.

\section{Materials and Methods}

This study is a cross sectional study which was done in a tertiary hospital in Riyadh, Saudi Arabia in the outpatient department of otolaryngology and head \& neck surgery, It was done by performing serial tympanograms and comparing the results between 2 groups

a) Type A: Normal tympanic membrane (control group) and

b) Type C: Retracted tympanic membrane group.

\section{Study Subjects}

\section{a) Inclusion Criteria:}

i. Every third Saudi adults (above age of 13) patient that presented to the otology clinic.

ii. Male and female patients.

iii. Patients that presented to the clinic from first of October 2016 to end of march 2017.

iv. Patients with tympanogram type $\mathrm{A}$ and $\mathrm{C}$.

b) Exclusion Criteria:

i. pediatric (bellow 13 years of age) Patients.

ii. Patients with tympanogram type B.

iii. Any patient with craniofacial anomalies

\section{Study Design}

This study is a cross-sectional study.

\section{Sample Size}

The sample size of this study is 161 years who fulfilled our inclusion and exclusion criteria.

\section{Sampling Technique:}

The sampling technique we used is systemic randomization. We included every third Saudi adult patient that presented to the otology clinic.

Data Collection Methods, Instruments Used, And Measurements

\section{Instruments Used}

a. GSI TympStar Version 1 Middle-Ear Analyzer:

b. It is a computer-based admittance instrument designed to be used in clinical or research settings. The TympStar is based on the sophistication, functionality and flexibility of the GSI 33, offering unparalleled testing capabilities.

In this study:

i. Admittance $(\mathrm{Y})$ was measured with a probe tone frequency of $226 \mathrm{~Hz}$ in a Screening tympanometry mode (Automatic).
ii. P-RANGE daPa: Normal.
iii. START daPa: +200 .
iv. Gradient: Tymp Width daPa.
v. P-RATE daPa/s: 600/200.

\section{Diagnostic Criteria}

\section{Tympanometry Normative Data}

a) Based on the British Society Of Audiology:

i. Tympanic peak pressure and middle ear pressure:

ii. Under carefully controlled conditions the $95 \%$ range in normal subjects is -20 to $+20 \mathrm{daPa}$, though pressures from -50 to +50 daPa can be considered normal in adults; pressures down to -100 daPa may be of a little clinical significance in isolation.

iii. Admittance or compliance:

iv. Compliance is normally in the range 0.3 to $1.6 \mathrm{~cm}^{3}$ in adults; $0.2 \mathrm{~cm}^{3}$ is acceptable as the lower limit in children aged less than 6 years but over 6 months.

v. Ear-canal volume:

vi. Typical values for ear-canal volume (ECV) are between $0.6-1.5 \mathrm{~cm}^{3}$ for adults.

b) Based on studies reviewed in Hunter and Shahnaz (2013).

\section{All Patients underwent 4 tympanograms}

i. Tympanogram I: patients underwent a baseline tympanogram.

ii. Tympanogram II: patients were asked to perform Valsalva maneuver, then immediately underwent a second tympanogram. 


\section{Global Journal of Otolaryngology}

iii. Typanogram III: patients were asked to take a 10 minutes break, then underwent a third tympanogram.

iv. Tympanogram IV: Patients were asked to perform Toynbee maneuver, then underwent a fourth tympanogram.

\section{Data Management and Analysis}

The data was analyzed using SPSS. Tympanogram variables were analyzed which included: external auditory canal volume, pressure, compliance and gradient. The mean, standard deviation, and confidence interval were calculated.

\section{Ethical Consideration}

Confidentiality was maintained. The research was fully explained to all the participants, and an informed consent was obtained from each participant, patients were told that they were free to withdraw from the research whenever they wished.

\section{Results}

Table 1: Demographic Data.

\begin{tabular}{|c|c|c|}
\hline & Group Type A & Group Type C \\
\hline Male & $54(41.5 \%)$ & $15(48.4 \%)$ \\
\hline Female & $76(58.5 \%)$ & $16(51.6 \%)$ \\
\hline Mean Age ( Standard Error) & $35.46(1.353)$ & $32.61(2.883)$ \\
\hline
\end{tabular}

A total of 161 ears were enrolled in this study. Type A tympanogram were found in 130 ears $(80.75 \%)$ and type $C$ were in 31 years $(19.25 \%)$. The mean age for type A tympanogram participant was 35.46 ( \pm 1.353 ) years and for type $C$ was 32.61 ( \pm 2.88 ) years. Among the type A group, 54 (41.5\%) subjects were male, and 76 (58.5\%) were female, while 15 (48.4\%) subjects were male and 16 (51.6\%) were female in type C group Table
1. There was no significant difference between the type A and type $\mathrm{C}$ group with respect to demographic characteristics. The tympanometry parameters for type $\mathrm{A}$ and $\mathrm{C}$ groups that were obtained in pre-Valsalva (I), immediate post-Valsalva (II), 10 minutes post-Valsalva (III) and immediately post-Toynbee maneuver (IV) are illustrated in Tables 2 \& 3 respectively.

Table 2: Type A tympanogram Group.

\begin{tabular}{|c|c|c|c|c|}
\hline Type A group & E.C.V & Pressure & Compliance & Gradient \\
\hline Tympanometry I & 1.1577 & 8.9231 & 0.6438 & 83.6047 \\
\hline Tympanometry II & 1.1985 & 22.3846 & 0.6815 & 79.5736 \\
\hline Tympanometry III & 1.1762 & 10.9231 & 0.6546 & 86.5116 \\
\hline Tympanometry IV & 1.1754 & $-9.7308-$ & 0.6892 & 85.4310 \\
\hline
\end{tabular}

In type A group, the mean pressure parameters were compared between tympanometry I, II, III, and IV Table 4. There were significant pressure differences between tympanometry II and I, II and III, I and IV and between tympanometry IV and III $(p$-values $=0.00)$. Conversely, there was no significant difference in pressure between tympanometry III and I (p-value= 0.343) which indicate that Valsalva and Toynbee maneuvers had a significant effect on pressure parameter, but the effect of Valsalva last less than 10 minutes.

Table 3: Type C tympanogram Group.

\begin{tabular}{|c|c|c|c|c|}
\hline Type C group & E.C.V & Pressure & Compliance & Gradient \\
\hline Tympanometry I & .9677 & $-187.5862-$ & 0.7103 & 109.7826 \\
\hline Tympanometry II & 1.0258 & $-141.0345-$ & 0.7103 & 93.0435 \\
\hline Tympanometry III & 1.0290 & $-155.0000-$ & 0.6767 & 100.4348 \\
\hline Tympanometry IV & 0.9968 & $-151.5517-$ & 0.7379 & 104.1667 \\
\hline
\end{tabular}

Table 4: Comparing pressure parameter between Tympanometry I,II,III \& IV in type A tympanogram group.

\begin{tabular}{|c|c|c|c|}
\hline Type A group & Mean & Standard Error Mean & P-value \\
\hline Pressure-II vs Pressure-I & 13.46154 & 2.537 & 0.000 \\
\hline Pressure-II vs Pressure-III & 11.46154 & 2.428 & 0.000 \\
\hline Pressure-III vs Pressure-I & 2.00000 & 23.98 & 0.343 \\
\hline Pressure-I vs Pressure-IV & 18.65385 & 4.6 & 0.000 \\
\hline Pressure-IV vs Pressure-III & $-20.65385-$ & 4.43309 & $0 . .000$ \\
\hline
\end{tabular}

Table 5: Comparing pressure parameter between Tympanometry I,II,III \& IV in type C tympanogram group.

\begin{tabular}{|c|c|c|c|}
\hline Type C group & Mean & Standard Error Mean & P-value \\
\hline Pressure-I vs Pressure-II & -46.55172 & 16.024 & 0.007 \\
\hline Pressure-III vs Pressure-II & -21.72414 & 8.129 & 0.012 \\
\hline Pressure-I vs Pressure-III & -34.33333 & 15.056 & 0.03 \\
\hline Pressure-I vs Pressure-IV & -31.72414 & 15.035 & 0.04 \\
\hline Pressure-IV vs Pressure-III & $-2.24138-$ & 5.28490 & 0.675 \\
\hline
\end{tabular}

In the other hand, Table 5 illustrates comparisons of middle ear pressures between tympanometry I, II, III, and IV in type C group. We can clearly see that Valsalva maneuver had a significant effect on middle ear pressure (tympanometry II I). However, and its effect lasted more than 10 minutes as the middle ear pressure did not go back to baseline and Toynbee maneuver did not have a significant on middle ear pressure as shown in tympanometry III-I, III-IV, (p-value: 0.03 and 0.675 respectively). 


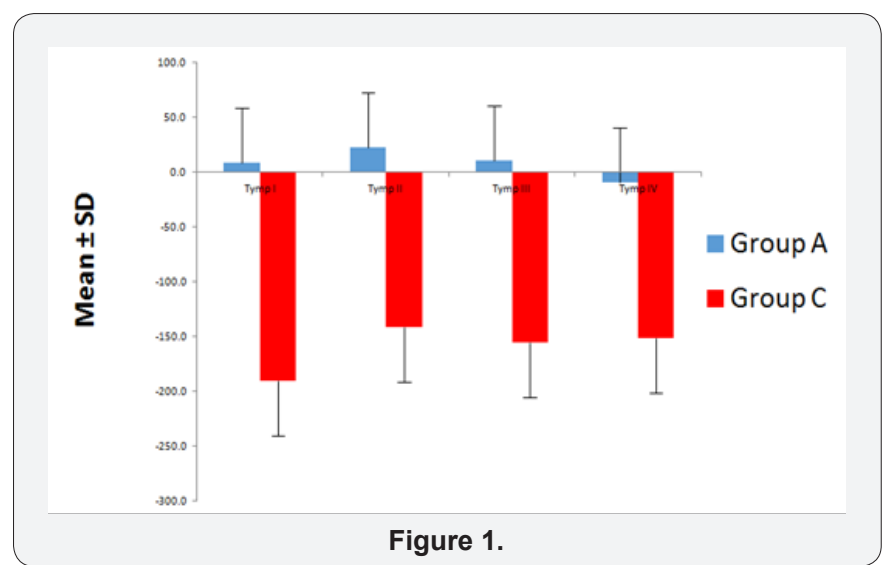

Comparisons in the changes of pressure with different maneuvers between type A and C tympanogram are shown in Table 6 and Figure 1. The pressure change in tympanometry I and II was significantly different between type A than in type C tympanogram group ( $\mathrm{p}$-value $=0.074$ ) which is explained by the much larger change in pressure in type $\mathrm{C}$ group with Valsalva maneuver. Also, comparing pressure change in tympanometry I and III between type A and C tympanogram group showed significant difference due to the fact that in type A group the pressure went back to baseline while in type $C$ it did not and was maintained for longer than 10 minutes. Additionally, Type A tympanogram group had significant pressure change in tympanometry II and III when compared to type C tympanogram group for the same reason mentioned above.

Table 6: Pressure change between type A \& type C tympanogram groups.

\begin{tabular}{|rr|c|c|c|}
\hline & Mean & $\begin{array}{c}\text { Standard } \\
\text { Error Mean }\end{array}$ & P-value \\
\hline Diff_Tymp_I_II_pressure & A & 19.4615 & 2.21515 .77 & 0.074 \\
& C & 48.9655 & & \\
\hline Diff_Tymp_I_III_pressure A & 15.1538 & 1.63514 .09 & 0.046 \\
& C & 44.6667 & & \\
\hline Diff_Tymp_II_III_pressure A & 19.0000 & 2.0286 .556 & 0.043 \\
C & 33.4483 & & \\
\hline
\end{tabular}

\section{Discussion}

Tympanometry is a test that measures the tympanic membrane impedance. It's helpful in diagnosing middle ear pathologies along with Eustachian tube diseases [4]. Valsalva maneuver is a maneuver which is done by blowing against pinched nostrils and a closed mouth. It increases the middle ear pressure, pushing the tympanic membranes laterally. Toynbee is the exact opposite, it's done by closing the mouth and nostrils and swallowing, which creates negative pressure in the middle ear, retracting the tympanic membranes medially. Kumazawa, et al. [5] used tympanometry combined with the aforementioned maneuvers to diagnose Eustachian tube diseases. He took baseline tympanometry measurements for his patients, then asked them to perform Valsalva and Toynbee, and took other tympanometry measurements. He then categorized his patients into 3 categories: patients with normal Eustachian tube function are those whose middle ear pressure increased after performing Valsalva and decreased after performing Toynbee, patients with dysfunctional Eustachian tube are those whose middle ear pressure failed to decrease after performing Toynbee, and patients with patulous Eustachian tube are those whose middle ear pressure increased and decreased instantly following Valsalva without the need to perform Toynbee [6].

In type A group, as shown in the results, Valsalva maneuver increased middle ear pressure significantly. However, this did not last for 10 minutes and the pressure went back almost to baseline as we can see in the insignificant difference between tympanometry III and I. Toynbee maneuver also had a significant effect in reducing the middle ear pressure. In the other hand, not only Valsalva maneuver showed a larger significant effect on middle ear pressure in type $\mathrm{C}$ group, the effect lasted longer than 10 minutes and Toynbee maneuver did not reverse it showing evidence of Eustachian tube dysfunction in this group.

\section{Conclusion}

Our data suggests that, Valsalva maneuver had a significant effect on middle ear pressure in both normal population and on those with retracted tympanic. Although Valsalva effect did not last for 10 minutes in normal ears, it was found to have a larger and longer lasting effect on those ears with retracted tympanic membrane. Valsalva maneuver is an effective temporary line of management for symptomatic patient with retracted tympanic membrane. Toynbee was found to be effective in normal ears, but it did not show a significant effect on patient with retracted tympanic membrane.

\section{References}

1. Hidir Y, Ulus S, Karahatay S, Satar B (2011) A comparative study on efficiency of middle ear pressure equalization techniques in healthy volunteers. Auris Nasus Larynx 38(4): 450-455.

2. Doyle WJ, Seroky JT, Alper CM (1995) Gas exchange across the middle ear mucosa in monkeys. Estimation of exchange rate. Arch Otolaryngol Head Neck Surg 121(8): 887-892.

3. Canali I, Rosito LPS, Siliprandi B, Giugno C, Costa SSD (2017) Assessment of Eustachian tube function in patients with tympanic membrane retraction and in normal subjects. Braz J Otorhinolaryngol, 83(1): 50-58.

4. Steele David J, Jeffrey Susman, Fredrick A Mc Curdy (2003) Student Guide To Primary Care. ( $1^{\text {st }}$ edn.); Hanley \& Belfus, Philadelphia, USA.

5. (2007) Prevention of Middle Ear Barotrauma. Staff Washington, USA.

6. Kumazawa Tadami, Iwao Honjo, Keiji Honda (1977) Aerodynamic Pattern of Eustachian Tube Dysfunction. Archives of Oto-RhinoLaryngology 215(3-4): 317-323. 


\section{Your next submission with Juniper Publishers} will reach you the below assets

- Quality Editorial service

- Swift Peer Review

- Reprints availability

- E-prints Service

- Manuscript Podcast for convenient understanding

- Global attainment for your research

- Manuscript accessibility in different formats ( Pdf, E-pub, Full Text, Audio)

- Unceasing customer service

Track the below URL for one-step submission https://juniperpublishers.com/online-submission.php 